\title{
Research Ethics on Oral Health Case Series Report
}

\section{Viroj Wiwanitkit ${ }^{*}$}

Hainan Medical University, China

The case series is an accumulation of interesting cases for analysis. It is considered as a kind of descriptive study. As a research, there has to be a good research design, good methodology and ethical control. The ethics in researching is a big topic in the present. Several kinds of misconduct can be seen such as plagiarism, falsification and fabrication. In oral health care report, the ethical standard is set and the journal is against any kind of research misconduct. The approval of ethical clearance by local committee for any research is needed. In reporting, patient right and privacy have to be maintained. In addition, the verification of the dilemma ethical issue by ethicist is warranted. Not only the ethical concerns for research conducting but also concerns on reporting and publication should be addressed. In a recent publication, it is noted that the problem emerges from China [1,2]. Several researchers used paid service for performing researches, writing research report, making a pseudo-reviewer team and having pseudoscience predator publisher for complete the process of their researches. This is a totally unwanted event. It is a basic rule that there must be no any form of disguising. To keep the ethical practice should be kept in mind of everyone on the academic communities of oral health case report.

\section{References}

1. Hvistendahl M (2015) Academic misconduct. China pursues fraudsters in science publishing. Science. 27: 350: 1015.

2. Tian X, Song GM (2015) China's Medical Research Integrity. Lancet 10: 386 : e17.
*Corresponding author: Viroj Wiwanitkit, Professor, Hainan Medical University, China; Adjunct professor, Joseph Ayobabalola University, Nigeria, Wiwanitkit House, Bangkhae, Bangkok, 10160, Thailand, E-mail:wviroj@yahoo.com

Received: November 21, 2015; Accepted: November 28, 2015; Published: December 12, 2015

Citation: Wiwanitkit V (2015) Research Ethics on Oral Health Case Series Report. Oral health case Rep 1:e107. doi:10.4172/2471-8726.1000e107

Copyright: (c) 2015 Wiwanitkit V. This is an open-access article distributed under the terms of the Creative Commons Attribution License, which permits unrestricted use, distribution, and reproduction in any medium, provided the original author and source are credited. 